Article

\title{
Polyamine-Promoted Growth of One-Dimensional Nanostructure-Based Silica and Its Feature in Catalyst Design
}

\author{
Xin-Ling Liu ${ }^{1}$, Pei-Xin Zhu ${ }^{2}$, Yan-Feng Gao ${ }^{1}$ and Ren-Hua Jin ${ }^{3, *}$
}

1 Shanghai Institute of Ceramics, Chinese Academy of Sciences, 1295 Dingxi Road, Shanghai 200050, China; E-Mails: 1x1081115@gmail.com (X.-L.L.); gaosic@gmail.com (Y.-F.G.)

2 Synthetic Chemistry Lab., Kawamura Institute of Chemical Research, 631 Sakado, Sakura 285-0078, Japan; E-Mail: zhu@kicr.or.jp

3 Department of Material and Life Chemistry, Faculty of Engineering, Kanagawa University and JST-CREST, 3-2-7 Rokkakubashi, Yokohama 221-8686, Japan

* Author to whom correspondence should be addressed; E-Mail: rhjin@kanagawa-u.ac.jp; Tel.: +81-45-481-5661 (ext. 3845); Fax: +81-45-413-9770.

Received: 12 September 2012; in revised form: 23 September 2012 / Accepted: 24 September 2012 / Published: 1 October 2012

\begin{abstract}
Crystalline linear polyethyleneimine (LPEI) is a fascinating polymer that can be used as a catalyst, template and scaffold in order to direct the formation of silica with controllable compositions and spatial structures under mild conditions. Considering the crystallization and assembly of LPEI is temperature-dependent, we adopted different accelerated cooling processes of a hot aqueous solution of LPEI in order to modulate the LPEI crystalline aggregates. We then used them in the hydrolytic condensation of alkoxysilane. A series of silica with nanofibrils, nanotubes and nanowire-based structures were achieved simply by the LPEI aggregates which were pre-formed in defined cooling processes. These specific one-dimensional nanoscale structures assembled into microscale fibers-, sheet- and platelet-like coalescences. Furthermore, the deposition kinetics was also researched by the combination of other characterizations (e.g., $\mathrm{pH}$ measurement, ${ }^{29} \mathrm{Si}$ MAS NMR). As a preliminary application, the hybrids of LPEI@ $\mathrm{SiO}_{2}$ were used not only as an agent for reducing $\mathrm{PtCl}_{4}{ }^{2-}$ into $\mathrm{Pt}$ but also as host for loading $\mathrm{Pt}$ nanoparticles. The Pt-loaded silica showed good catalytic properties in the reduction of Rhodamine B by dimethylaminoborane (DMAB).
\end{abstract}


Keywords: biomimetic silicification; polyethyleneimine; crystalline aggregates; nanostructured silica; silica nanotube; silica nanowire

\section{Introduction}

Tailoring materials on controlled architectures and compositions is of lasting importance for materials scientists since the properties and performance of materials are strongly dependent upon their structured compositions. One route to approach a tailor-made goal is so-called biomimicry: learning from nature to design and control chemical reactions and domain growths. In nature, silica in diatoms and sponges possess fascinating and diverse patterns on many length scales, which inspires scientists to develop the so-called bioinspired/biomimetic synthetic strategies [1-5].

Accumulated knowledge on biosilicification has revealed that a family of long-chain polyamines in organisms plays several key roles in the fabrication of silica: (i) Long-chain polyamines self-assemble into defined structures to act as templates and scaffolds for directing the spatial structure of silica; (ii) the specific functional groups contained in the long-chain polyamines can promote the hydrolysis and condensation of silica source and the subsequent aggregation of silica species. Taking these considerations into biomimetic synthesis, two facets are worthy for probing: One is to design and synthesize long-chain polyamines analogue polymers and the other is to manipulate their assembly manners in various ways. A lot of work in this respect has been reported in the past ten years [6-14]. As a unique biomimetic approach, we have established a linear polyethyleneimine (LPEI)-based methodology to construct nanostructured silica and titania under mild conditions. Due to its crystalline nature of LPEI, 1D structure-based silica materials could be easily obtained in a two-step process. Namely, the crystalline LPEI aggregates were firstly obtained by naturally cooling hot aqueous solutions of LPEI to room temperature, and silica deposited on the preorganized LPEI aggregates after the addition of a silica source. In our method, developing LPEI crystalline assemblies with spatial characteristics is a key step because both the temporal issue of the sol-gel reaction and the spatial issue of the product morphologies are controlled by the LPEI assemblies (templates). Therefore, tailoring the architecture of silica with special structures needs to modulate the LPEI crystalline aggregates that control the silica formation temporally and spatially. We have found many simple factors such as solvents, $\mathrm{pH}$, concentrations and additives to modulate LPEI aggregates from aqueous solution during the natural cooling process [15-24]. In spite of the differences on the parameters based in these modulations, a common point was shared. That is, LPEI crystallized and grew maturely into fibrous bundles via which were lack in 1D-structure with well-controlled length and width in the nanoscale.

To overcome some shortcomings of our previous methods and to achieve the diverse technique of sophisticated silica processing seen in biological systems, we further attempted to develop controllable and scalable approaches for modulating 1D structure-based LPEI aggregates and their directing silica formation. Since the crystallization of LPEI is temperatures-dependent, it was expected that nucleation and growth of crystalline LPEI aggregates should be controlled by the temperature change in the cooling process. To confirm this idea, several accelerated cooling processes different from the previous natural cooling was chosen and conducted by the direct addition of given amounts of the crushed ice to 
hot aqueous solution of LPEI. Indeed, LPEI@ $\mathrm{SiO}_{2}$ with tunable sizes and morphologies (i.e., fibrils, tubes, wires) in the nano-dimensions could be easily scalable (gram-scale) under different cooling processes, and the morphologies in the micro-scale were correspondingly changed. Furthermore, the modulation of the amount of LPEI and silica source was employed to not only control the compositions, porosity, and surface areas but also to understand some details of the biomimetic silicification. Additionally, a preliminary feature of the silica in catalysis was also explored by loading Pt nanoparticles on LPEI@SiO 2 .

\section{Results and Discussion}

To achieve an accelerated cooling process, crushed ice was employed to control the temperature change. As shown in Table 1, four typical accelerated cooling processes named with Process-I, -II, -III and -IV were introduced by the addition of 4, 10, 25 and $50 \mathrm{~g}$ of ice, respectively. After addition of crushed ice to the hot LPEI solution, the temperature of the mixture decreased quickly in a short time. For Process-I, the temperature decreased rapidly from $85{ }^{\circ} \mathrm{C}$ to about $39{ }^{\circ} \mathrm{C}$ in $1 \mathrm{~min}$ and then slowly decreased to room temperature; for Process-II, it reached the lowest temperature of about $12{ }^{\circ} \mathrm{C}$ in $1 \mathrm{~min}$; for Process -III and -IV, it decreased the lowest temperature of $1{ }^{\circ} \mathrm{C}$ in $1 \mathrm{~min}$.

Table 1. Temperature changes after addition of crushed ice.

\begin{tabular}{|c|c|c|c|c|}
\hline & Process-I & Process-II & Process-III & Process-IV \\
\hline & \multicolumn{4}{|c|}{ Ice addition } \\
\hline Hot aqueous solution & \multicolumn{4}{|c|}{ Crystalline LPEI } \\
\hline $\begin{array}{l}\text { linear polyethyleneimine } \\
\text { (LPEI) wt \% (Amount) }\end{array}$ & $\begin{array}{c}2,5,10 \\
(10 \mathrm{~g})\end{array}$ & $\begin{array}{c}2,5,10 \\
(10 \mathrm{~g})\end{array}$ & $\begin{array}{c}2,5,10 \\
(10 \mathrm{~g})\end{array}$ & $\begin{array}{c}2 \\
(10 \mathrm{~g})\end{array}$ \\
\hline Amount of ice added $(\mathrm{g})$ & 4 & 10 & 25 & 50 \\
\hline $\begin{array}{c}\text { The lowest temperature after } \\
\text { addition of ice }\end{array}$ & $39^{\circ} \mathrm{C}$ & $12^{\circ} \mathrm{C}$ & $1^{\circ} \mathrm{C}$ & $1^{\circ} \mathrm{C}$ \\
\hline
\end{tabular}

Our first interest here is screening whether the crystalline LPEI aggregates generated by the differently accelerated cooling processes afford the specially structured silica after mixing the LPEI aggregates with MS-51 (methyl silicate-51, a commercially available silica source with 5-mer tetramethoxysilane). Therefore, we subjected the silica powders obtained from Process-I, -II and -III to TEM and SEM observation. Interestingly, as seen in the in Figure 1, the products of LPEI@SiO $\mathrm{Sia}_{2}$ different cooling processes showed different morphologies and sizes. In the case of Process-I, the produced LPEI@ $\mathrm{SiO}_{2}$ appeared larger bundles in which a lot of one-dimensional nano structures (ribbon-like fibrils) coalesced each other. This is likely the case of natural cooling hot LPEI solution to room temperature in our previous reports [15]. Under the dramatically accelerated cooling conditions, however, the produced LPEI@ $\mathrm{SiO}_{2}$ turned into the forms of nanotube-based platelets (in Process-II) and nanowires-based platelets (in Process-III). The size of the platelets in Process-II ranged from 5 to $10 \mu \mathrm{m}$ but became small, below $5 \mu \mathrm{m}$, in Process-III. Interestingly, a lot of nanotubes with approximately $20 \mathrm{~nm}$ in diameter or nanowires approximately $10 \mathrm{~nm}$ in diameter knitted closely and 
densely each other forming platelets in which the nanotubes or nanowires grew nearly straightly towards the edge of platelets without embedding the ends in the platelets body. The nanotubes are approximately $3 \mathrm{~nm}$ hollow inside. In contrast, the silica mediated by the process-IV showed irregular fibrils-based bundles in which the fibrils are likely assemblies of irregular nanoparticles with an average size of $15 \mathrm{~nm}$, i.e., necklace-like structure (see Figure S1 in the Supporting Information). Therefore, it is conclusive that the morphologies and the fine structures of the 1D LPEI@ $\mathrm{SiO}_{2}$ hybrids are easily controllable through different cooling processes.

Figure 1. The transmission electron microscope (TEM) (left column) and scanning electron microscope (SEM) (right column) images of LPEI@, $\mathrm{SiO}_{2}$ obtained under different cooling processes by fixing $10 \mathrm{~g}$ of $2 \mathrm{wt} \% \mathrm{LPEI}$ and $10 \mathrm{~mL}$ of $10 \mathrm{vol} \% \mathrm{MS}-51$. From up row to bottom one, $m_{\text {ice }}$ increased from 4 , to 10 , to $25 \mathrm{~g}$, and corresponded to Process-I, -II, -III, respectively. Scale bars: (d), $1 \mu \mathrm{m} ;(\mathbf{e})-(\mathbf{f}), 2.5 \mu \mathrm{m}$. Where LPEI was linear polyethyleneimine, MS-51 was methyl silicate-51.
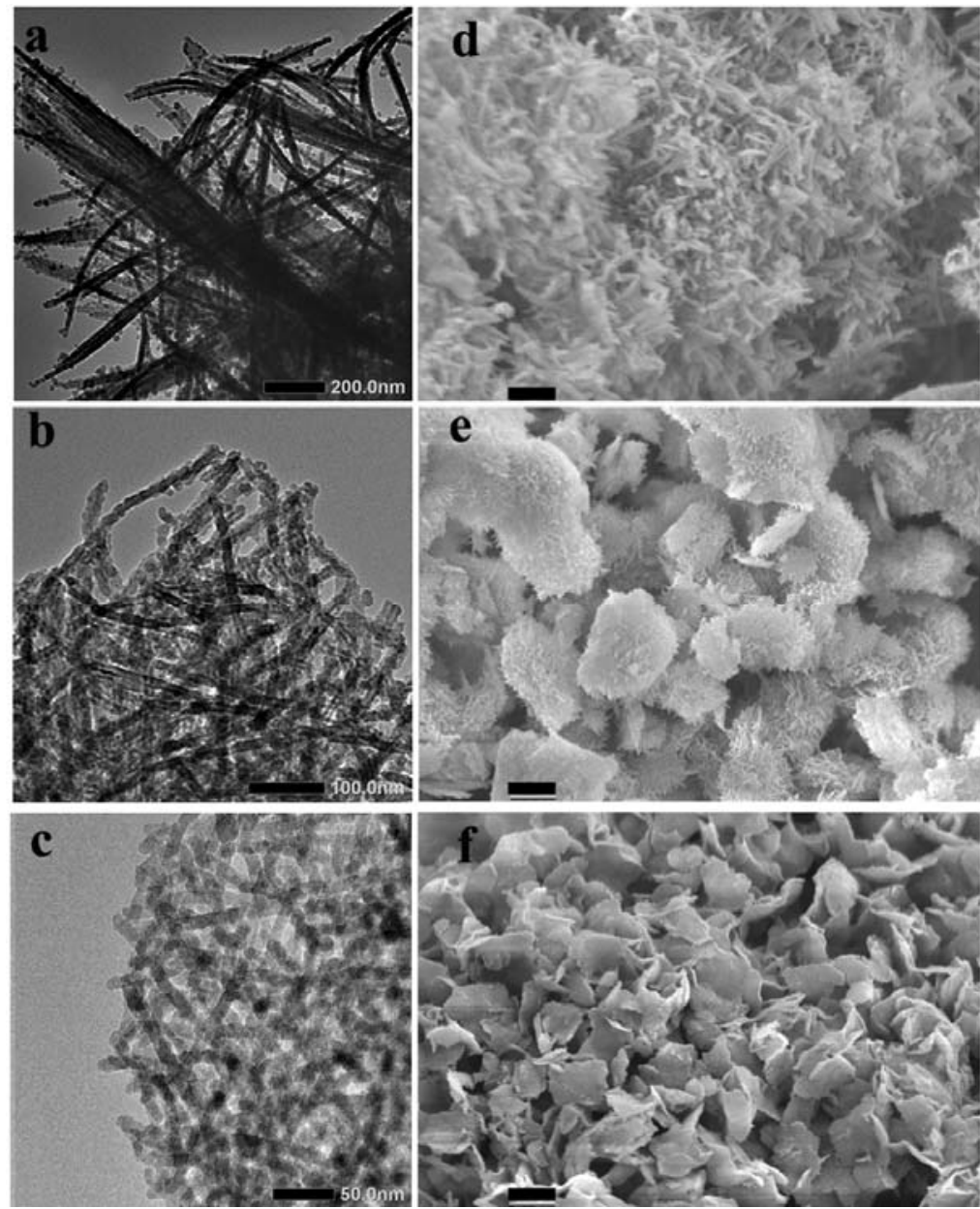

Here, we can see a tendency towards the differences of 1D LPEI@ $\mathrm{SiO}_{2}$ in nano-structure correlating to the morphologies variance in the micro-scale. This is attributed to the growth of the LPEI crystallites. In the previously mentioned three cooling process I-III, the final concentration of the LPEI and the lowest temperature after addition of ice decreased with increasing the amount of ice added. Despite an effect of quickly lowering temperature from above $85{ }^{\circ} \mathrm{C}$ to below $40{ }^{\circ} \mathrm{C}$ in 
Process-I, this quenching method did not affect to change the resulted silica structure compared to naturally cooling method in the conditions of the same concentration of LPEI. As seen in Figure 1d, the LPEI@SiO $\mathrm{SiO}_{2}$ hybrids obtained in Process-I were mainly composed of bundles of fibers with diameters of several hundred nanometers and length of several micrometers. In our previous work, it was confirmed that the concentrations ranging $0.5 \sim 5 \mathrm{wt} \%$ LPEI resulted in the same ribbon-like fibrous silica bundles in the naturally cooling conditions [15]. Both in the Process-II and -III, the resulted silica powders have platelet-like morphologies, which are transcribed from LPEI precursors. This indicates that the suddenly quenched temperature arriving below $12^{\circ} \mathrm{C}$ within $1 \mathrm{~min}$ is effective to change the growing direction of LPEI crystallites from bundles to platelets in which a lot of crystalline wires of LPEI crossly overlapped each other to form mat-like plates.

Since this biomimetic silicification included the pre-assembly of crystalline LPEI and post-deposition of silica, the amounts of LPEI and MS-51 may also impose control on the surface areas, porosity and compositions. Taking the Process-II as an example, we examined the silica deposition by changing the concentrations of LPEI and MS-51. In the TG-DTA analysis of the hybrids (see Figure S4 of TG-DTA charts), two endothermic peaks around $230-250{ }^{\circ} \mathrm{C}$ and $360-380{ }^{\circ} \mathrm{C}$ are observed, which can be attributed to the decompositions of LPEI. The mass ratios of silica/LPEI calculated based on the mass loss around $150 \sim 800{ }^{\circ} \mathrm{C}$ were listed in Table 2 . It is evident that the LPEI@ $\mathrm{SiO}_{2}$ hybrids resulted from higher concentrations of LPEI possess lower content of silica while the hybrids given upon higher concentrations of MS-51 trend to deposit plenty of silica.

Table 2. Composition of LPEI@ $\mathrm{SiO}_{2}$ hybrids obtained from different conditions.

\begin{tabular}{ccccc}
\hline & & \multicolumn{3}{c}{ MS-51(in vol \%) } \\
\cline { 3 - 5 } & & $\mathbf{1 0 \%}$ & $\mathbf{2 0 \%}$ & $\mathbf{3 0 \%}$ \\
\cline { 2 - 5 } & & $\mathrm{SiO}_{2} / \mathrm{LPEI}$ & $\mathrm{SiO}_{2} / \mathrm{LPEI}$ & $\mathrm{SiO}_{2} / \mathrm{LPEI}$ \\
\hline LPEI & $\mathbf{2}$ & $77 / 23$ & $82 / 18$ & $81 / 19$ \\
concentration & $\mathbf{5}$ & $62 / 38$ & $73 / 27$ & $75 / 25$ \\
(wt \%) & $\mathbf{1 0}$ & $54 / 46$ & $65 / 35$ & $68 / 32$ \\
\hline
\end{tabular}

We calcined the LPEI@SiO $\mathrm{SiO}_{2}$ hybrids at $800{ }^{\circ} \mathrm{C}$ and subjected the remained silica powders to $\mathrm{N}_{2}$ adsorption-desorption measurement to understand the characteristics in surface area and pore size distributions. It was found that the typical $\mathrm{N}_{2}$ adsorption-desorption isotherms for the calcined silica showed characteristic hysteresis loops as seen in porous materials and the pore size distribution ranged between approximately 5-30 nm (Figure S3). Such mesoporosity would be caused by the hollow structure of silica nanotube and the intergrain voids, which are constructed in the platelet piled up by a lot of 1D-structured nanosilica. It was found that the mesoporosity became smaller for the silica that was prepared under high concentrations of MS-51. Practically, the BET surface areas $\left(\mathrm{S}_{\mathrm{BET}}\right)$ largely related with the concentrations of LPEI (wt \%) and MS-51 (vol \%), which can be clarified in Figure 2. It is apparent that the values of $\mathrm{S}_{\mathrm{BET}}$ for the silica elevated with increasing LPEI concentrations while declined with increasing MS-51 concentrations (Figure 2). Herein, the values of $\mathrm{S}_{\mathrm{BET}}$ can be divided into three ranges based on LPEI concentrations: $100-200 \mathrm{~m}^{2} / \mathrm{g}$ for LPEI being $2.0 \%, 250-350 \mathrm{~m}^{2} / \mathrm{g}$ for $5.0 \%$ and $350-500 \mathrm{~m}^{2} / \mathrm{g}$ for $10 \%$ (in weight). Obviously, the higher concentration of LPEI was used, the larger surface area of silica was produced. This means that the LPEI enclosed in silica can play as a 
pore-directing agent; the more LPEI the more pores. On the other hand, $\mathrm{S}_{\mathrm{BET}}$ decreased about $100 \mathrm{~m}^{2} / \mathrm{g}$ when concentration of MS-51 changed from 10\% to 30\% (in vol \%), indicating that the relatively less amount of MS-51 are favorable to increase surface area of the silica. This is consistent with the increment of mesoporosity under lower concentration of MS-51. We confirmed that the $\mathrm{SiO}_{2}$ calcined at $800{ }^{\circ} \mathrm{C}$, did not show morphological damage.

Figure 2. BET surface areas of $\mathrm{SiO}_{2}$ obtained by removing LPEI. Black line: 2\% LPEI; Red line: 5\% LPEI; Green line: 10\% LPEI.

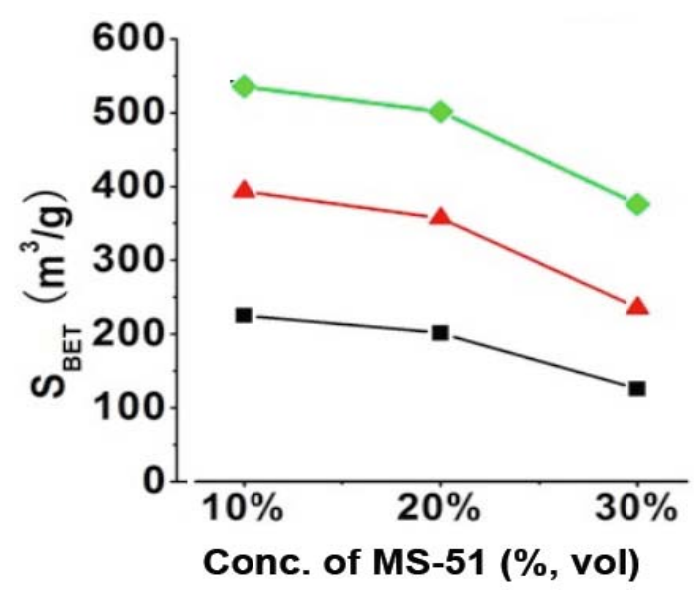

As pointed out by the results above, the 1D structure-based silica could be successfully modulated by the simple sudden cooling of the hot LPEI solution. The following issues are more about the details of the silicification process ranging from crystallization and assembly of LPEI to surface deposition of silica. Considering that the cooling was in fact a process of precipitation accompanying crystallization and rearrangement of LPEI chains, the nucleation and growth were hence interfered by the temperature change. For example, in Process-III with a strongly accelerated cooling process, the temperature suddenly reached $1{ }^{\circ} \mathrm{C}$. This would cause a decrease of dissolved LPEI molecules in the solutions since LPEI is not soluble in water at ambient temperature condition. Because the formation of crystalline LPEI depends on the dissolved LPEI chains, which diffuse toward the as-formed nuclei, the growth and extension of the crystallites were then suppressed in this too quick cooling process. Consequently, the crystallization proceeded more rapidly with disordered fractions, compared with the long-range diffusion, and the nuclei were abundantly formed in a short time. In addition, in this case a part of LPEI molecules, which are independent of whether the thermodynamically most favored configuration is achieved, reached on the crystal surface and were incorporated into the crystal with amorphous state. As a result, short LPEI nano-wires with loose and irregular arrangements of LPEI chains were formed. This loose state allowed the permeation of silica source into the cores of LPEI nano-wires, leading to the formation of LPEI@ $\mathrm{SiO}_{2}$ with solid appearance seen in TEM images. In Process II with an adequate cooling process, on the contrary, the crystallization proceeded more slowly compared with diffusion and the growth and rearrangement were supported, resulting in nano-fibers with rigid and regular arrangement of LPEI chains. This rigid structure is capable of blocking the permeation of silica source into the cores. In consequence, silica was mainly deposited on the surfaces to form silica shell. In this case, the TEM image just appeared as a tubular hollow structure. To some extent, the DSC data may further confirm the viewpoints above. The LPEI aggregates obtained via 
different cooling process were used for DSC analysis, and the typical heating curve was displayed in Figure 3a. The integrated heat of fusion (denoted as $\mathrm{S}_{\mathrm{H}}$ ) on the heating curve was employed to judge the crystallinity $[25,26]$. By plotting the ratios of $\mathrm{S}_{\mathrm{H}} / \mathrm{S}_{\mathrm{HO}}$ against $m_{\text {ice }}$ (where $\mathrm{S}_{\mathrm{H}}$ is based the samples obtained under the conditions in the presence of ice and $\mathrm{S}_{\mathrm{HO}}$ in the absence of ice), we compared the crystallinity of the LPEI aggregates. As seen in Figure 3b, the ratios declined with the increase of $m_{\text {ice, }}$ meaning that the crystallinity decreased. If the LPEI chains arranged irregularly and the crystalline LPEI backbone was short, less energy is needed for the melting of crystalline LPEI and the ratio of $\mathrm{S}_{\mathrm{H}} / \mathrm{S}_{\mathrm{HO}}$ would be estimated to be low. The ratio of $\mathrm{S}_{\mathrm{H}} / \mathrm{S}_{\mathrm{HO}}$ in Process-I $\left(m_{\text {ice }}=4 \mathrm{~g}\right)$ was about $97 \%$, which indicates that our cooling process is near that in a natural cooling one. Indeed, the fibrous morphologies in the SEM are quite similar to our previous reports. But with increasing the ice amount (i.e., decrease of $\mathrm{S}_{\mathrm{H}} / \mathrm{S}_{\mathrm{HO}}$ ), the evident morphological changes in the resulted silica happened. Although the detailed and complex assembly processes of crystalline LPEI are not clear, from the resulted silica structure, we can expect that in the accelerated cooling process the short and individual crystalline nano-wires of LPEI were geometrically favorable to link and knit each other growing to be the platelet-like or film-like morphologies. However, within the non-accelerated cooling system, the formed long nano-fibers of LPEI became difficult to assembly on a planar film, and finally presented as fibrous bundles as seen in SEM image.

Figure 3. Differential scanning calorimetry (DSC) curve and integrated heat of fusion $\left(\mathrm{S}_{\mathrm{H}}\right)$ of samples under different cooling processes (different $m_{\text {ice }}$ ) by fixing $5 \%$ LPEI.

(a) Typical DSC curve; (b) Plot of ratios of $\mathrm{S}_{\mathrm{H}} / \mathrm{S}_{\mathrm{HO}}$ against $m_{\text {ice. }}$.
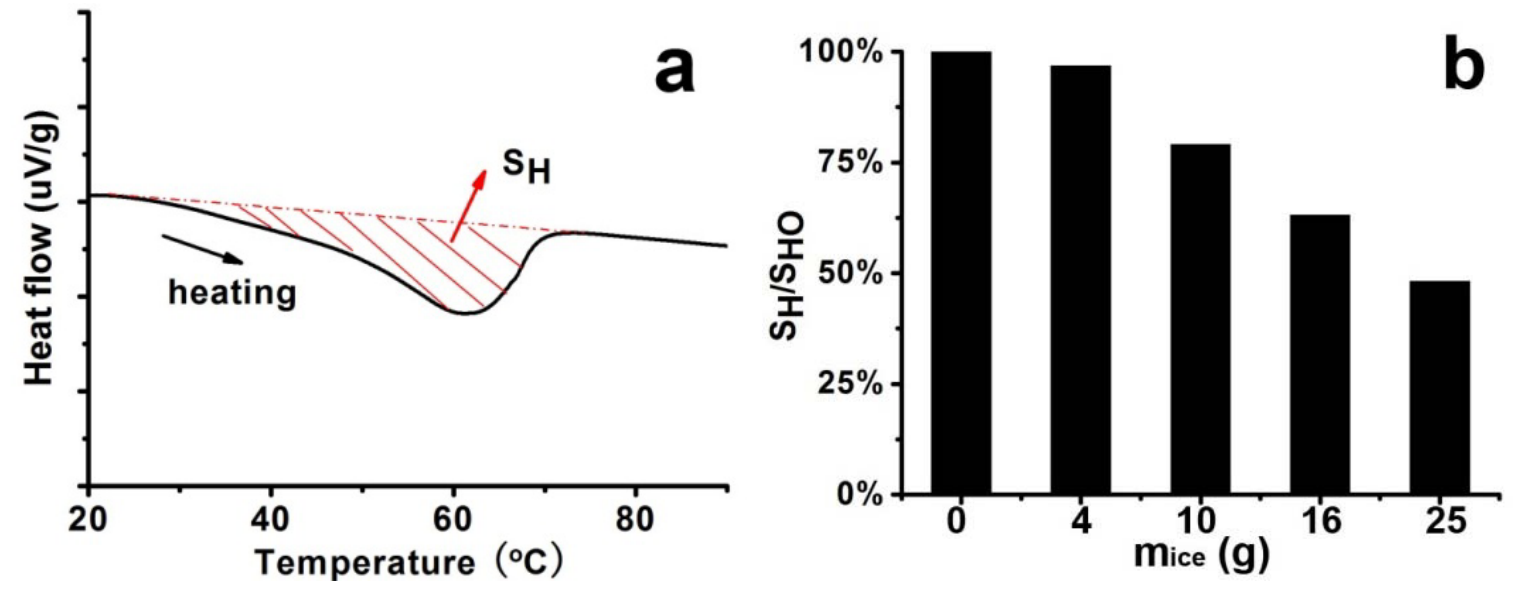

The second issue to be discussed is that of the silica deposition process on the LPEI surfaces. After the organization and crystallization of LPEI in the first stage, it was suggested that the amorphous LPEI existing on the crystalline backbone promotes the hydrolytic condensation of MS-51. To monitor the deposition process, the dynamic $\mathrm{pH}$ change was recorded as shown in Figure 4. Here, the starting point to determine the $\mathrm{pH}$ value was the time of mixing the hot LPEI solution with crushed ice. During the initial $30 \mathrm{~min}$, the hot LPEI solution cooled down to thermo-equilibrium state. At $30 \mathrm{~min}$, MS-51 was added, and stirred for $60 \mathrm{~min}$ to complete the hydrolytic condensation reaction. Figure 4a shows the dynamic change of $\mathrm{pH}$ within different processes. It can be seen that after 15 min following the addition of ice, the $\mathrm{pH}$ began to plateau, indicating the closing of the crystallization. After the addition of MS-51, it also took approximately $15 \mathrm{~min}$ for the $\mathrm{pH}$ to become steady, meaning that the deposition 
of silica proceeded quickly to a large degree. In spite of the differences of $m_{\text {ice, }}$, the $\mathrm{pH}$ curves are fairly similar. In Figure 4b, the influence of MS-51 concentration on the $\mathrm{pH}$ was also investigated. Obviously, the final $\mathrm{pH}$ was correlated with concentrations of silica source. When MS-51 concentration was 30\%, the final $\mathrm{pH}$ even closed to 6 , indicating that high concentration of silica source led to low $\mathrm{pH}$ value.

Figure 4. Time-course of $\mathrm{pH}$ change. (a) $\mathrm{pH}$ change curves under different cooling processes (different $m_{\text {ice}}$ ) by fixing 5 wt \% LPEI and 10 vol \% MS-51; (b) pH change curves under different concentrations of MS-51 by fixing $10 \mathrm{wt} \%$ LPEI in Process-II $\left(m_{\text {ice }}=10 \mathrm{~g}\right)$.
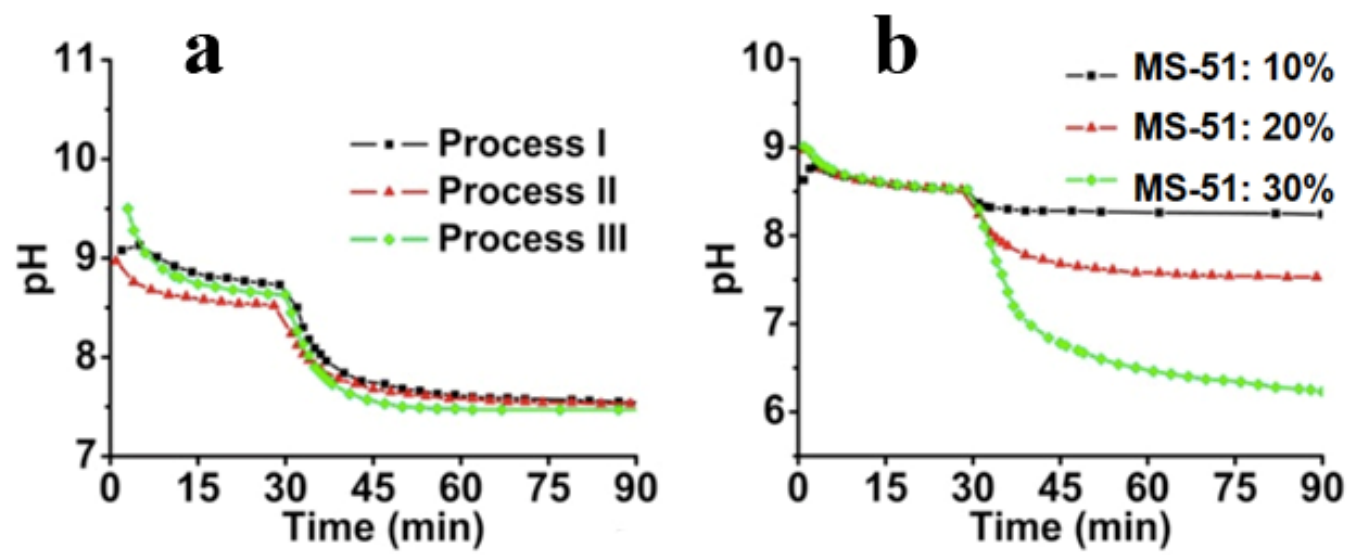

The decline of $\mathrm{pH}$ offers us some information on LPEI-SiO ${ }_{2}$ interfaces. In the hot LPEI solution, because a lot of the - NH- functional groups in LPEI, which was dissolved molecularly, can accept protons from $\mathrm{H}_{2} \mathrm{O}$, the hot solution should be relatively basic. After cooling, the LPEI self-assemble to aggregates and a limited amount of - $\mathrm{NH}$ - group will be localized on the surface of LPEI aggregates and forms an interface with water. This interface offers free $\mathrm{OH}^{-}$in water phase so that $\mathrm{pH}$ value appears above 8.5. Choosing Process-II as a typical instant, we compared the influences of the concentration of MS-51 on the $\mathrm{pH}$ values in silica deposition. As seen in Figure 4b, after the addition of MS-51, the $\mathrm{pH}$ began to decrease with time. Here, the final $\mathrm{pH}$ after 90 min appeared at 8.4, 7.5 and 6.3 , respectively, when MS-51 was $10 \%, 20 \%$ and $30 \%$. To address the decline of $\mathrm{pH}$, it is necessary to mention the mechanism of the amine group on LPEI aggregates in promoting the hydrolytic condensation of alkoxysilane. In fact, the groups of -NH- on LPEI aggregates play as catalysts for hydrolysis and condensation of alkoxysilane. During the progress of hydrolytic condensation, silica deposited around the exposed amine groups on the surface of LPEI aggregate and thus $\mathrm{LPEI}-\mathrm{H}_{2} \mathrm{O}$ interface was quickly replaced by LPEI-SiO 2 . Consequently, the silica shell formed surrounding LPEI aggregates will neutralize the LPEI because the silica is weakly acidic, resulting in the $\mathrm{pH}$ decline. Figure $4 \mathrm{~b}$ indicates unambiguously that when the mass of silica shell surrounding LPEI is low (i.e., MS-51 concentration is low), the declined degree of $\mathrm{pH}$ is small. In contrast, as mass of silica deposited is high, the declined degree of $\mathrm{pH}$ is large (i.e., the $\mathrm{pH}$ is lowered evidently). In addition, we can say that the silica deposition capacity become large when the concentration of LPEI was increased to $5 \%$. In this case, $10 \% \mathrm{MS}-51$ ( $1 \mathrm{~mL}$ of MS-51 in $9 \mathrm{~mL}$ ethanol) is insufficient for terminating the surface power to silica deposition. 
Moreover, the silica obtained under different concentrations of MS-51 while fixing LPEI concentration in Process-II was subjected to measurement of ${ }^{29} \mathrm{Si}$ CPMAS NMR spectra (Figure 5). Two signals on the NMR spectra at $-100 \mathrm{ppm}$ and $-110 \mathrm{ppm}$ are assigned to Q3 (HOSi(OSi-) 3 ) and Q4 $\left(\mathrm{Si}(\mathrm{OSi}-)_{4}\right)$, respectively. The estimated ratio of Q3/Q4 increased from 0.62 , to 0.89 , to 1.20 as the concentrations of MS-51 changed from 10, to 20 and to $30 \mathrm{vol} \%$. Considering the hydrolytic condensation process of silica source, at the beginning the polycondensation grows towards branching dimension with a sufficient number of siloxane bonds ( $\mathrm{Si}-\mathrm{O}-\mathrm{Si}$ ) due to basicity of the surfaces of LPEI templates. However, as the mass of silica shell surrounding the LPEI aggregates increased, the basicity of its surface decreased. This basicity decline will suppress the branching growing of $\mathrm{Si}-\mathrm{O}-\mathrm{Si}$ but allow the polycondensation growing with linear fashion. Consequently, the Q4 bonding fraction decreased while Q3 bonding fraction increased when deposited silica increased (i.e., at the higher concentration of MS-51).

Figure 5. ${ }^{29} \mathrm{Si}$ CPMAS NMR spectra of the samples under different concentrations of MS-51 by fixing $10 \mathrm{wt} \%$ LPEI in Process-II $\left(m_{\text {ice }}=10 \mathrm{~g}\right)$. Insert: schematic description of amorphous silica. Black line: 10 vol \% MS-51; Red line: 20 vol \% MS-51; Green line: 30 vol \% MS-51.

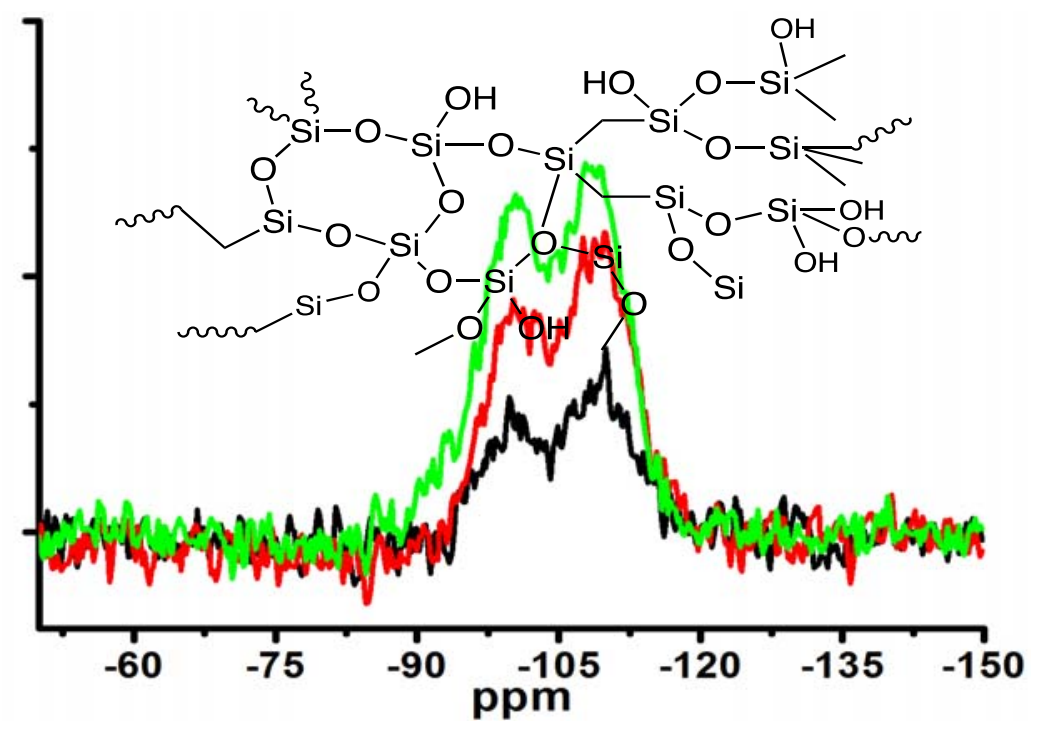

The process of using the crushed ice to modulate the LPEI crystallization and subsequent silica deposition is quite convenient for scalable production of silica platelets with elemental one-dimension structures. For example, about $10 \mathrm{~g}$ of hybrid sample could be collected under the conditions as follows: LPEI (5 wt \%, $100 \mathrm{~g}), 160 \mathrm{~g}$ of ice, MS-51 (30 vol \%, $100 \mathrm{~mL}$ ). These hybrids showed the sheet-like platelets appearance with nanowire-knitted structure inside (Figure S5).

It is known that LPEI can act as a reducing agent and therefore the as-prepared LPEI@ $\mathrm{SiO}_{2}$ can play both as reducing agent and host [19]. As an application, the LPEI@ $\mathrm{SiO}_{2}$ hybrids obtained under the conditions of (Process-III, $m_{\text {ice }}=25 \mathrm{~g}, 5 \mathrm{wt} \%$ LPEI and $30 \mathrm{vol} \% \mathrm{MS}-51$ ) were employed to load Pt nanoparticles as catalyst. Here, just simply mixing $\mathrm{PtCl}_{4}{ }^{2-}$ solutions with LPEI@ $\mathrm{SiO}_{2}$ powders, we loaded the Pt nanoparticles on the silica. As shown in Figure 6a, the HRTEM shows that Pt homogeneously distributed around the silica. The XRD pattern also shows the characteristic peaks of 
Pt (Figure S5). Since metallic nanoparticles can be used as catalysts in the organic reactions [27-30], we used the Pt-loaded $\mathrm{SiO}_{2}$ as a catalyst in the reduction of Rhodamine B by DMAB. As shown in Figure 6b, after mixing the catalyst of Pt-loaded $\mathrm{SiO}_{2}$ with the solution of containing $\mathrm{RhB}$ and $\mathrm{DMAB}$, the absorption at around $553 \mathrm{~nm}$ of $\mathrm{RhB}$ decreased dramatically with almost de-colored state only within $11 \mathrm{~min}$. In contrast, the solution without addition of the Pt-loaded $\mathrm{SiO}_{2}$ showed little color change even after $24 \mathrm{~h}$. This contrast indicates that the Pt-loaded $\mathrm{SiO}_{2}$ is an active catalyst for the reduction of RhB by DMAB. As for the catalytic mechanism, the Pt nanoparticles loaded on silica wire can play as electron pool where the electrons from DMAB are trapped on Pt and then passed to RhB.

Figure 6. (a) High-resolution transmission electron microscopy (HRTEM) images of Pt-loaded LPEI@SiO $\mathrm{Si}_{2}$; (b) Time-course spectra of Rhodamine B (RhB) reduced by dimethylaminoborane (DMAB).
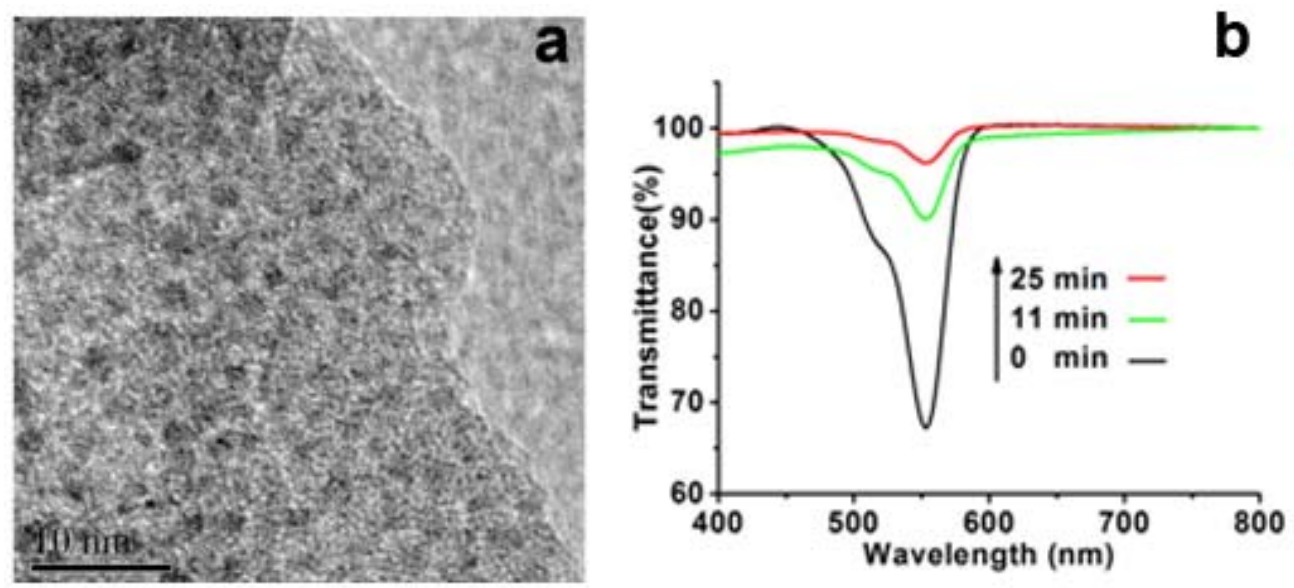

\section{Experimental Section}

\subsection{Typical Synthesis of LPEI@SiO 2 Hybrids}

The preparation of LPEI (average molecular weight 20000 ) was previously reported [15]. To $10 \mathrm{~g}$ of LPEI solution ( $5 \mathrm{wt} \%$ ), which was heated to $85^{\circ} \mathrm{C}$ in advance, was added immediately $10 \mathrm{~g}$ of crushed ice under magnetic stirring. This led to a dramatic decrease of the solution temperature to about $12{ }^{\circ} \mathrm{C}$ in $1 \mathrm{~min}$ and resulted simultaneously in aggregates of LPEI to form a suspension. After $30 \mathrm{~min}$, the suspension temperature rose to room temperature. Then, to this suspension $10 \mathrm{~mL}$ of 10 vol \% of methyl silicate-51 (MS-51 a commercially available silica source with 5-mer tetramethoxysilane) in ethanol was added. This mixture was stirred for $1 \mathrm{~h}$ at room temperature. Finally, the precipitates were collected by centrifugation, washed by ethanol, and dried at $60{ }^{\circ} \mathrm{C}$ under vacuum for $24 \mathrm{~h}$.

In the present work, the concentrations of LPEI were adjusted to 2,5 and $10 \mathrm{wt} \%$ before the addition of crushed ice. Three typical accelerated cooling processes were selected according to the amount of ice (denoted as $m_{\text {ice }}: 4 \mathrm{~g}, 10 \mathrm{~g}$, and $25 \mathrm{~g}$ ) and a temperature detector monitored the temperature change. Under each process, the concentrations of LPEI solution (10 g) with 2, 5 and $10 \mathrm{wt} \%$ and the volume concentrations of MS-51 in ethanol solution $(10 \mathrm{~mL})$ with 10, 20 and $30 \mathrm{vol} \%$ were also 
considered as control factors. To get silica, LPEI in the hybrids was removed by calcination at $800{ }^{\circ} \mathrm{C}$ for $3 \mathrm{~h}$ after a heating process of $5 \mathrm{~h}$ from room temperature to $800^{\circ} \mathrm{C}$.

\subsection{Loading Pt Nanoparticles on LPEI@SiO ${ }_{2}$ Hybrids}

$0.04 \mathrm{~g}$ of LPEI@ $\mathrm{SiO}_{2}$ powders obtained under the condition of $\left[m_{\mathrm{ice}}=25 \mathrm{~g}, 2 \mathrm{wt} \% \mathrm{LPEI}(10 \mathrm{~g})\right.$, 10 vol \% MS-51 $(10 \mathrm{~mL})$ ] were mixed with $10 \mathrm{~mL}$ of $\mathrm{Na}_{2} \mathrm{PtCl}_{4}$ solution $(0.02 \mathrm{M})$. After stirring for $30 \mathrm{~min}$ under room temperature, the solution was shaken at $85{ }^{\circ} \mathrm{C}$ for $30 \mathrm{~min}$. Then the Pt loaded LPEI@SiO $\mathrm{SiO}_{2}$ powders (Pt-LPEI@SiO $\mathrm{SiO}_{2}$ ) were obtained by centrifugation. To evaluate the catalytic activity, $10 \mathrm{mg}$ of Pt-LPEI@ $\mathrm{SiO}_{2}$ were mixed with $2 \mathrm{~mL}$ of Rhodamine B $(\mathrm{RhB})(8 \mathrm{ppm})$ and $7 \mathrm{~mL}$ of $\mathrm{H}_{2} \mathrm{O}$. After a stirring of $30 \mathrm{~min}, 1 \mathrm{~mL}$ solution containing the reducing agent of DMAB (dimethylaminoborane, $\left(\mathrm{CH}_{3}\right)_{2} \mathrm{NH} \cdot \mathrm{BH}_{3}, 0.2 \mathrm{~mol} / \mathrm{L}$ ) was added to the mixture, and the absorption spectra of $\mathrm{RhB}$ in supernatant was monitored using a UV-Vis spectrometer.

\subsection{Characterizations}

The morphologies of the products were observed by SEM (Kyence, VE9800) and TEM (JEOL, JEM-2200FS). The thermal decomposition behaviors were monitored by TG/DTA (SII Nano technology Inc., Japan, TG-DTA 6300). The BET surface areas were obtained from $\mathrm{N}_{2}$ absorption-desorption experiments performed on a Flow Sorb II 2300 Instrument (Micromeritics). The XRD patterns were recorded on a diffractometer (Rigaku-Denki RX-7) with $\mathrm{CuK}_{\alpha}$ radiation. The polycondensation degree of silica framework was estimated by the ${ }^{29} \mathrm{Si}$ CPMAS NMR spectra recorded on a JEOL-400 MHz NMR spectrometer. The melting behavior of LPEI aggregates under different cooling rates was monitored by DSC measurements (Perkin-Elmer DSC-6) with a heating rate of $10{ }^{\circ} \mathrm{C} / \mathrm{min}$. The absorption spectra of Rhodamine $\mathrm{B}$ were recorded on Hitachi U-4100 spectrophotometer.

\section{Conclusions}

In summary, a novel and scalable approach to regulate the structures and morphologies of silica was reported. Through the control of the crystallization and assembly of LPEI by simply changing cooling process with crushed ices, we can prepare tunable templates that are able to lead site-selectively to multiple morphologies of silica in a broad-scale length with nanofibers, nanotube and nanowire skeletons. Alongside the variation of the amounts of LPEI and silica source, the compositions and surfaces areas of LPEI@Silica can be further tuned. The results help us not only understand the specific roles of the three factors but also elucidate the silica deposition kinetic process. Using this biomimetic method, nanostructured silica with diverse patterns guided by LPEI can be easily and scalably available. As an example for application of the silica, Pt nanoparticles were loaded on the as-prepared silica, which showed a good catalysis for the reductions of RhB by DMAB.

\section{Acknowledgments}

This research was partly supported by Core Research for Evolutional Science and Technology (CREST), Japan Science and Technology Corporation (JST). 


\section{References}

1. Dove, P.M.; Yoreo, J.J.D.; Weiner, S. Reviews in Mineralogy and Geochemistry: Biomineralization; The Mineralogical Society of America Geochemical Society: Washington, DC, USA, 2003.

2. Baeuerlein, E. Biomineralization: Progress in Biology, Molecular Biology and Application; Wiley-VCH: Weinheim, Germany, 2004.

3. Patwardhan, S.V. Biomimetic and bioinspired silica: Recent developments and applications. Chem. Commun. 2011, 47, 7567-7582.

4. Brutchey, R.L.; Morse, D.E. Silicatein and the translation of its molecular mechanism of biosilicification into low temperature nanomaterial synthesis. Chem. Rev. 2008, 108, 4915-4934.

5. Dickerson, M.B.; Sandhage, K.H.; Naik, R.R. Protein- and peptide-directed syntheses of inorganic materials. Chem. Rev. 2008, 108, 4935-4978.

6. Kröger, N.; Deutzmann, R.; Bergsdorf, C.; Sumper, M. Species-specific polyamines from diatoms control silica morphology. Proc. Nat. Acad. Sci. USA 2000, 97, 14133-14138.

7. Sumper, M.; Kroger, N. Silica formation in diatoms: The function of long-chain polyamines and silaffins. J. Mater. Chem. 2004, 14, 2059-2065.

8. Delak, K.M.; Sahai, N. Amine-catalyzed biomimetic hydrolysis and condensation of organosilicate. Chem. Mater. 2005, 17, 3221-3227.

9. Patwardhan, S.V.; Clarson, S.J.; Perry, C.C. On the role(s) of additives in bioinspired silicification. Chem. Commun. 2005, 1113-1121.

10. Robinson, D.B.; Rognlien, J.L.; Bauer, C.A.; Simmons, B.A. Dependence of amine-accelerated silicate condensation on amine structure. J. Mater. Chem. 2007, 17, 2113-2119.

11. Belton, D.J.; Patwardhan, S.V.; Annenkov, V.V.; Danilovtseva, E.N.; Perry, C.C. From biosilicification to tailored materials: Optimizing hydrophobic domains and resistance to protonation of polyamines. Proc. Natl. Acad. Sci. USA 2008, 105, 5963-5968.

12. Minguet, E.G.; Vera-Sirera, F.; Marina, A.; Carbonell, J.; Blázquez, M.A. Evolutionary diversification in polyamine biosynthesis. Mol. Biol. Evol. 2008, 25, 2119-2128.

13. Bernecker, A.; Wieneke, R.; Riedel, R.; Seibt, M.; Geyer, A.; Steinem, C. Tailored synthetic polyamines for controlled biomimetic silica formation. J. Am. Chem. Soc. 2009, 132, 1023-1031.

14. Masse, S.; Laurent, G.; Coradin, T. Influence of cyclic polyamines on silica formation during the Stober process. Phys. Chem. Chem. Phys. 2009, 11, 10204-10210.

15. Jin, R.-H.; Yuan, J.-J. Synthesis of poly(ethyleneimine)s-silica hybrid particles with complex shapes and hierarchical structures. Chem. Commun. 2005, 1399-1401.

16. Yuan, J.-J.; Jin, R.-H. Multiply shaped silica mediated from aggregates of linear poly(ethyleneimine). Adv. Mater. 2005, 17, 885-888.

17. Jin, R.-H.; Yuan, J.-J. Simple synthesis of hierarchically structured silicas by poly(ethyleneimine) aggregates pre-organized by media modulation. Macromol. Chem. Phys. 2005, 206, 2160-2170.

18. Yuan, J.-J.; Jin, R.-H. Fibrous crystalline hydrogels formed from polymers possessing a linear poly(ethyleneimine) backbone. Langmuir 2005, 21, 3136-3145. 
19. Yuan, J.-J.; Zhu, P.-X.; Fukazawa, N.; Jin, R.-H. Synthesis of nanofiber-based silica networks mediated by organized poly(ethylene imine): Structure, properties, and mechanism. Adv. Funct. Mater. 2006, 16, 2205-2212.

20. Zhu, P.-X.; Fukazawa, N.; Jin, R.-H. Polyethyleneimine aggregates regulated by metal cations acting as biomimetic organic reactors for silica architectures. Small 2007, 3, 394-398.

21. Jin, R.-H.; Yuan, J.-J. Biomimetically controlled formation of nanotextured silica/Titania films on arbitrary substrates and their tunable surface function. Adv. Mater. 2009, 21, 3750-3753.

22. Zhu, P.-X.; Jin, R.-H. Simple and efficient aqueous process for nanostructured fibrous $\mathrm{TiO}_{2}$ regulated by linear polyethyleneimine aggregates. Eur. J. Inorg. Chem. 2010, 3, 476-482.

23. Matsukizono, H.; Zhu, P.X.; Fukazawa, N.; Jin, R.H. Turbine-like structured silica transcribed simply by pre-structured crystallites of linear poly(ethyleneimine) bounded with metal ions. CrystEngComm 2009, 11, 2695-2700.

24. Matsukizono, H.; Jin, R.-H. Bent silica nanosheets directed from crystalline templates controlled by proton donors. J. Nanopart. Res. 2011, 13, 683-691.

25. Wunderlich, B. Macromolecular Physics; Academic Press: New York, NY, USA, 1980.

26. Mago, G.; Kalyon, D.M.; Fisher, F.T. Polymer crystallization and precipitation-induced wrapping of carbon nanofibers with PBT. J. Appl. Polym. Sci. 2009, 114, 1312-1319.

27. Jiang, Z.-J.; Liu, C.-Y.; Sun, L.-W. Catalytic properties of silver nanoparticles supported on silica spheres. J. Phys. Chem. B 2005, 109, 1730-1735.

28. Song, H.; Rioux, R.M.; Hoefelmeyer, J.D.; Komor, R.; Niesz, K.; Grass, M.; Yang, P.; Somorjai, G.A. Hydrothermal growth of mesoporous SBA-15 silica in the presence of PVP-stabilized Pt nanoparticles: Synthesis, characterization, and catalytic properties. J. Am. Chem. Soc. 2006, 128, 3027-3037.

29. Deng, Z.; Chen, M.; Wu, L. Novel method to fabricate $\mathrm{SiO}_{2} / \mathrm{Ag}$ composite spheres and their catalytic, surface-enhanced raman scattering properties. J. Phys. Chem. C 2007, 111, 11692-11698.

30. Fukuoka, A.; Kimura, J.-I.; Oshio, T.; Sakamoto, Y.; Ichikawa, M. Preferential oxidation of carbon monoxide catalyzed by platinum nanoparticles in mesoporous silica. J. Am. Chem. Soc. 2007, 129, 10120-10125.

(C) 2012 by the authors; licensee MDPI, Basel, Switzerland. This article is an open access article distributed under the terms and conditions of the Creative Commons Attribution license (http://creativecommons.org/licenses/by/3.0/). 